\title{
ECO-DRIVING ASSISTANCE SYSTEM: A NEW WAY OF HOW TO SAVE ENERGY
}

\author{
Lydie NOUVELIERE \\ IFSTTAR IM - LIVIC \\ University of Evry - IBISC \\ Versailles, France
}

\author{
Hong-Tu LUU \\ IFSTTAR IM - LIVIC \\ Versailles, France
}

\author{
Saïd MAMMAR \\ University of Evry - IBISC \\ Evry, France
}

\author{
Qi CHENG \\ IFSTTAR IM - LIVIC \\ Versailles, France
}

\author{
Olivier ORFILA \\ IFSTTAR IM - LIVIC \\ Versailles, France
}

\section{KEYWORDS}

Eco-Driving Assistance System (EDAS), CO2, emissions, driver support, low carbon vehicles, vehicle modeling, optimization.

\section{ABSTRACT \\ The work developed in this paper is realized within the ecoDriver EU FP7 project that is shortly presented in the first part of the paper. Among the several main objectives underlined by this project, one consists in developing a vehicle and energy consumption model to be validated and then used to help the driver to better drive in terms of consumption and safety, advised by a HMI (Human-Machine Interface) module. Several experimental results are shown to illustrate the obtained energy saving with such an EDAS and the legal speed respect.}

\section{INTRODUCTION}

In 2005 in France, 553 million tons of greenhouse gas (GHG) were emitted, thus decreasing the French crude emissions of $2 \%$ between 1990 and 2005. But in the same time, the emissions due to the transportation have increased by $22 \%$, and the transport represents one third of the total energy consumption. The governmental objective consists in reducing by $20 \%$ the energy consumption and the greenhouse emissions in the transports by 2020. The fuel consumption is responsible for $35 \%$ of the nation-wide emissions of $\mathrm{CO}_{2}$. The main GHG effect of rejections increases because of the strong raise of displacements (ADEME source, France).

Besides, because of the high oil prices/economical crisis and the stakes of the greenhouse effect reduction, more and more vehicle drivers look for a low energy consumption behavior. The economical-ecological way of driving (eco-driving) is a citizen driving behavior, which allows to reduce the energy consumption up to $15 \%$, limiting the GHG effect responsible for the climatic warming, and to decrease the risk of accidents (by 10 to $15 \%$ ).

Over the last few years, the French government has then incited the cars and trucks manufacturers and vehicle equipment manufacturers to bring some new concepts in vehicles development and their associated accessories (climate systems, rain sweeps,...) in such a way that these systems will consume less and less.

The French National Agency for the research also support the ABV project (low speed automation) for the development of new ADAS (Advanced Driving Assistance Systems) that will be safer and low energy consuming. In that sense, the European Union (EU) underlines this run-up through several EU research projects: HAVEit [2], eFuture [3] or ecoDriver [1].

This paper shortly presents the EU ecoDriver project (FP7), by insisting on the energy optimizing part. The principles of modeling the energy consumption are based on the calculation of the energy consumption (fuel, electricity) for a given traffic on a given road network.

Low energy consumption strategies and low emissions systems would require models, currently designed to follow the vehicles fleet behavior, able to characterize the fine kinematics variations of a single vehicle. Here an advisor system is presented, with some simulation and experimental results, for a light vehicle low consumption. The vehicle and consumption modeling are described with their inputs/outputs scheme. A first analysis in terms of obtained gain in consumption and legal speed respect is developed. 


\section{ECODRIVER PROJECT: PRESENTATION}

The project ecoDriver - Supporting the driver in conserving energy and reducing emissions - addresses the need to consider the human element when encouraging "green" driving, since driver behaviour is a critical element in energy efficiency. The focus of the project is on technology working with the driver. The project aims to deliver the most effective feedback to drivers on green driving by optimizing the driver-powertrainenvironment feedback loop. It will carry out a substantial programme of work to investigate how best to win the support of the driver to obtain the most energy-efficient driving style for best energy use.

Feedback coverage will include preview of the upcoming situation, optimizing the current driving situation as well as post-drive feedback and learning. The project will address this across a wide range of vehicles - e.g. cars, light trucks and vans, medium and heavy trucks and buses - covering both individual and collective transport, and will optimize feedback to drivers for both nomadic devices (smartphones, tablets) and built-in systems and compare the effectiveness of each. The project will evaluate HMIs and feedback to drivers via both nomadic devices and built-in systems and compare the effectiveness of each. In each case a range of HMIs and feedback styles will be assessed. The project aims to examine driving not only with present and near-term power trains but also with a full range of future vehicles, including various types of hybrid and plug-in electric vehicles. A comprehensive evaluation will be carried out both in the laboratory (a variety of driving simulators) and in real world driving in both the private and fleet contexts. Scenarios will be developed to assess the implications for the future effectiveness of green driving support. The target of ecoDriver is to deliver a $20 \%$ improvement in energy efficiency by autonomous means alone, which opens up the possibility of greater than $20 \%$ savings in combination with cooperative systems.

\section{BUILT-IN SYSTEM IN A MANUAL TRANSMISSION CAR}

Among the four test vehicles considered in the ecoDriver project for the powertrain model for green-driving, a middleclass passenger car with a conventional powertrain having at its disposal a manual transmission is chosen. The energy used is petrol and this test vehicle is already inserted in the commercial market and can be considered as a "man in the street" car (see Annex A for its description).

\section{Introduction and main outputs of the model}

A model will be used to compute an optimal speed profile and an optimal gear number to be followed by the driver if he wants to ecodrive "in the ecoDriver way". This driving assistance system is based on the knowledge of the incoming road cartography in its longitudinal and vertical axis. The model is built based on the vehicle dynamics (engine, gearbox, Differential, wheel, aerodynamic, road slope).
It has to be noted that the emissions will not be modeled, but an information feedback from the vehicle CAN bus can be made about the $\mathrm{CO}_{2}$ emissions (as the estimated output of the CAN bus $\mathrm{CO}_{2}$ internal model).

\section{Functional description of the model}

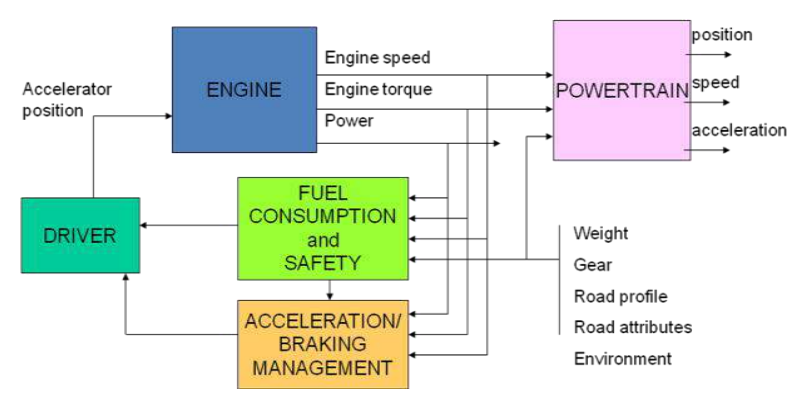

Fig. 1 - Schematic diagram of the powertrain model.

The functional description of the powertrain model is presented on figure 1. The approach considers that from road and vehicle data, an optimal profile in terms of speed and gear number is computed and sent to the HMI module developed in the project, this one being in interaction with the driver.

The ambition of the specified model is to combine safety requirements and fuel consumption reduction by optimizing the vehicle speed and the gear management. It then needs to know several kinds of data issued from the vehicle (speed, position, gear number), environment (longitudinal headway spacing), road (legal speed limitation, road geometrical attributes) to compute such an optimal profile.

The geometrical road attributes are interesting to compute a limit speed to enter a curve to be coming based on the curve geometry and the vehicle dynamics.

\section{Model family}

The vehicle model is based on the powertrain dynamics considering the different efforts interacting between the vehicle, the road and the environment. The fuel consumption is physically modeled from experimental data issued from the test vehicle (Annex A), under a physical relation.

\section{Model parameters}

Several parameters to be tuned are considered in the model : vehicle mass, wheel radius, wheel inertia, engine inertia, gearbox inertia, drag coefficient, rolling resistance, air mass density, differential ratio, gear ratios, gearbox efficiency, maximum engine torque (at given rpm), maximum power (at given rpm). 


\section{Model accuracy}

The vehicle and fuel consumption models must be designed and tuned in order to obtain at the least a $1 \mathrm{~s}$ refreshment of the HMI, this is coherent with the driver perception. Furthermore, the real-time constraint for the final experimental application in ecoDriver makes an electronic horizon use being compulsory. It will use the road data and the cartography.

\section{On board auxiliaries}

The only auxiliary taken into account in the model is the air conditioning in terms of spent power.

\section{Vehicle modeling}

TABle I. Nomenclature - Vehicle Parameters

\begin{tabular}{|c|c|}
\hline $\begin{array}{l}\text { Parameter } \\
\text { Notation }\end{array}$ & Parameter title \\
\hline$x$ & Longitudinal position (m) \\
\hline$v_{x}$ & Longitudinal speed $\left(\mathrm{m} \cdot \mathrm{s}^{-1}\right)$ \\
\hline$r$ & Wheel radius $(\mathrm{m})$ \\
\hline$M$ & Vehicle mass $(\mathrm{kg})$ \\
\hline$I_{e}, I_{t}, I_{d}, I_{w}$ & $\begin{array}{l}\text { Respective rotational inertias of the } \\
\text { engine, transmission, drive shaft, } \\
\text { wheel/axle shaft }\left(\mathrm{kg} \cdot \mathrm{m}^{2}\right)\end{array}$ \\
\hline$N_{f}, N_{t}$ & $\begin{array}{l}\text { Transmission numerical ratio and } \\
\text { final drive ratio }\end{array}$ \\
\hline$T_{e}$ & Engine torque (N.m) \\
\hline$\omega_{e}$ & Engine speed $\left(\mathrm{rad} . \mathrm{s}^{-1}\right)$ \\
\hline$g$ & Gravity $\left(\mathrm{m} \cdot \mathrm{s}^{-2}\right)$ \\
\hline$C_{R}$ & Rolling resistance \\
\hline$\rho$ & Mass density of air $\left(\mathrm{kg} \cdot \mathrm{m}^{-3}\right)$ \\
\hline$S$ & $\begin{array}{l}\text { Projected frontal area of the vehicle } \\
\left(\mathrm{m}^{2}\right)\end{array}$ \\
\hline$C_{x}$ & Aerodynamic drag coefficient \\
\hline$\theta$ & Road slope (rad) \\
\hline
\end{tabular}

A non slip longitudinal vehicle model is used to simulate the optimization module in order the vehicle to low fuel consume.

$$
\begin{aligned}
\dot{x}= & v_{x} \\
\dot{v}_{x}= & \frac{r}{M r^{2}+I_{e t} N_{f}^{2} N_{t}^{2}+I_{d w}}\left(\eta N_{f} N_{t} T_{e}\right. \\
& -r\left(M g C_{R}+\frac{1}{2} \rho S C_{x} v_{x}^{2}+M g \sin (\theta)\right)
\end{aligned}
$$

where

$$
I_{d w}=I_{d} N_{f}^{2}+I_{w} \text { and } I_{e t}=I_{e}+I_{t}
$$

\section{Fuel consumption modelling}

A consumption model developed in [10] is used

$$
\begin{aligned}
& f_{c}=\beta_{1}+\beta_{2} w_{e}+\beta_{3} w_{e} T_{e} \quad{ }_{4} T_{e} \quad{ }_{5} T_{e}^{2} \quad \text { if } T_{e} \quad 0 \\
& =\alpha+\gamma w_{e}+O w_{e}^{2} \quad \text { if } T_{e} 0
\end{aligned}
$$

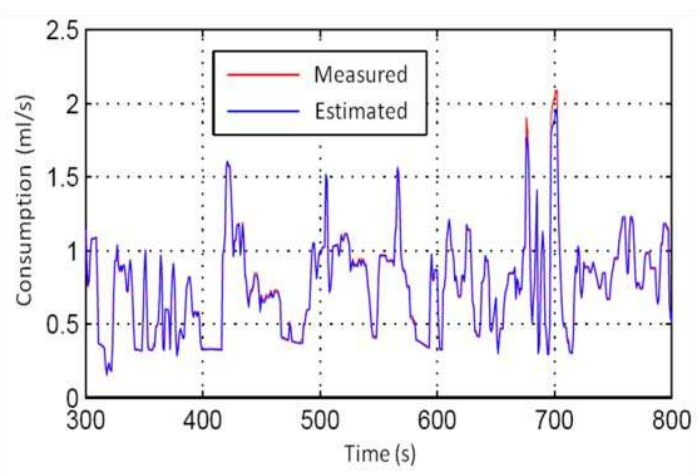

Fig. 2 - Comparison of the consumption model (2) with experimental data.

This fuel consumption model was determined in comparison with the different models encountered in the literature $[12,13,14]$. This relation is a function with the engine speed and the engine torque. Obviously, when the vehicle does not accelerate (engine braking), the engine torque is regarded as negative and only the engine speed is taken into account. In [10], it is shown that the estimation of the parameters of the consumption model (2) from experimental values of the fuel consumption for a light vehicle is not very high: less than $2.5 \%$ for the major part of the data. The figure 2 illustrates the experimental validation of this model with measured data.

\section{Optimization Module}

The proposed ADAS is based on a Dynamic Programming (DP) method used to calculate the optimal speed profile and the optimal gear number to be sent to the driver in real-time.

\section{Fuel Consumption Optimization: Methodology}

The fuel optimal control problem is formulated under its classical discrete form where $X_{k}=\left[\begin{array}{c}x_{k} \\ v_{x_{k}}\end{array}\right]$ is the state vector and $U_{k}=\left[\begin{array}{l}T_{e_{k}} \\ G_{k}\end{array}\right]$ is the control input which gathers the engine torque and the gear ratio. The DP method is then written

$J_{N}=\varsigma_{N}\left(X_{N}\right)$ for $k \quad N \quad 1 \ldots 0$

$J_{k}\left(X_{N}\right)=\min \left(\varsigma_{k}\left(X_{k}, U_{k}\right) \underset{U_{k}}{J_{k 1}}\left(f\left(X_{k}, U_{k}\right)\right)\right)$ 
with the criterium $J$ expressed as follows

$J=Q_{1} \cdot F C+Q_{2} \cdot T+Q_{3} \cdot S M O O T H$

where $F C=\sum_{k=0}^{k-1} f c_{k}\left(w_{e_{k}}, T_{e_{k}}\right)$ and $T$ is the trip time.

SMOOTH is the penalty induced by a speed change. It is used to obtain a smoother driving and is expressed by

$$
S M O O T H=\sum_{k=0}^{k-1}\left(\begin{array}{l}
A \cdot\left(\max \left(0, v_{x_{k+1}}-v_{x_{k}}\right)\right)+ \\
(1-A) \cdot \min \left(0, v_{x_{k+1}}-v_{x_{k}}\right) \mid
\end{array}\right.
$$

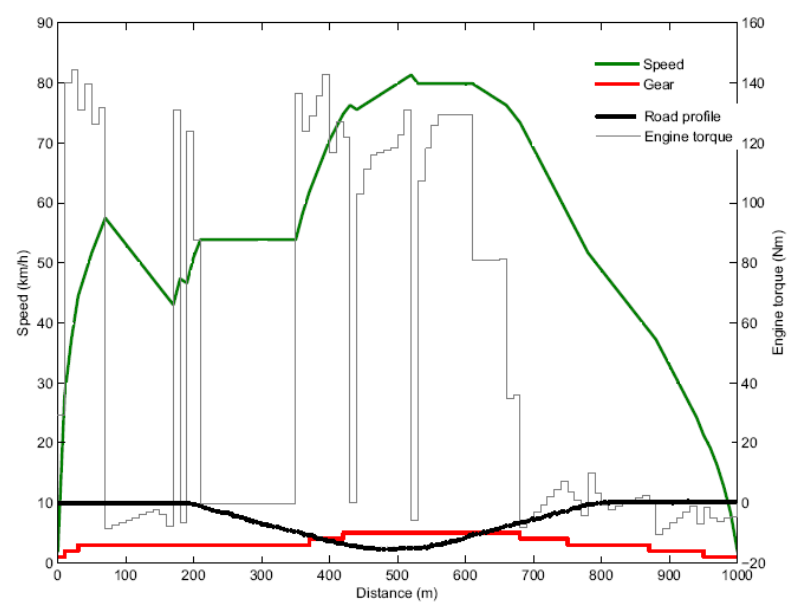

Fig. 3 - Optimal speed profiles and gear ratio versus weighed coefficient $Q_{i}$.

\section{Safety Criterion}

The legal speed and the safe headway spacing are two safety variables that are considered in this optimization module. The legal speed along the trip is known and stored in the embedded cartography and is regarded as a static safety information. The safe headway spacing is a dynamic out of the speeds of both following and preceding vehicles.

A safety margin is calculated and integrated in the optimization module as shown on the figure 4. A fuzzy approach is developed in [11] to obtain the safety margin and the consequence on the optimization module.

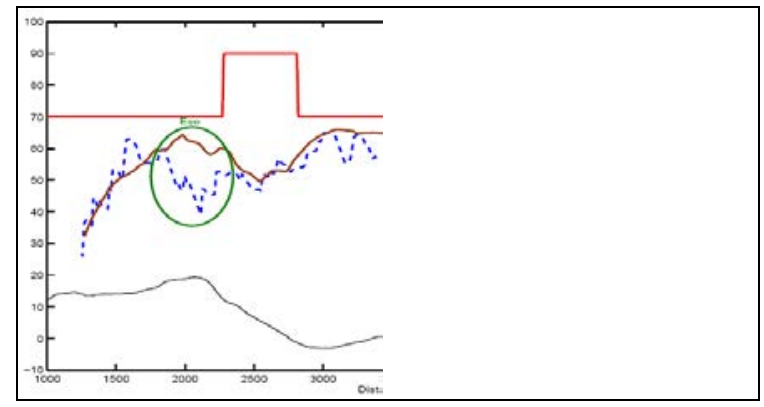

Fig. 4 - Optimal profiles with $Q 1=Q 2=Q 3=1$.
The figure 4 gives an example of the results obtained with such an EDAS where one can easily see an economical situation (green circle) and a safe situation (red circle). This EDAS is then implemented on a prototype light vehicle (Annex A).

\section{VEHICLE IMPLEMENTATION}

For the EDAS tests, two vehicles are used: a follower vehicle which is a RENAULT Clio $3 \mathrm{Eco} 2$ and a preceding vehicle equipped with a wifi system, a GPS receiver and an on-board computer.

In each vehicle, an on-board computer executes the different processing. In the preceding vehicle, it is received the GPS data, its longitudinal speed, its longitudinal acceleration and its covered distance thanks to the odometer of the follower vehicle. The follower vehicle uses its one to manage all the data acquisition processing, looking for the vehicle positions on the digital map, computing the optimal trajectories, transmitting the outputs to the driver via an HMI module whose development will be a main part of the ecoDriver project. The data transfer from one vehicle to the other is achieved by a wifi connecting channel. Each vehicle has a GPS receiver. A mapmatching algorithm in the follower vehicle permits it to determine the position of both vehicles on the digital map. This one acquires some data from the CAN bus: speed, acceleration, covered distance, engine speed. The engaged gear ratio is rebuilt from the speed and the engine speed. A laser radar measures the headway spacing that permits to obtain the relative speed.

\section{Tests Objectives}

Such a suggestive system efficiency highly depends on the driver reactions. It is then obvious to make several drivers driving in different ways in order to collect their first impression.

A free circulating scenario is proposed to these drivers to know their way of driving. Following this one, traffic conditions are added to take into account the safe headway (simulated by the preceding vehicle behavior in acceleration). The evaluation is then oriented into 3 directions: environmental (potential economical gain), mobility (trip time) and safety (improvement).

\section{Tests scenarios}

Eight voluntary drivers have realized the following scenarios distributed on 2 phases:

PH1: two drivers drive under a free circulating (no traffic constraint), in order to validate the fuel economy effect. Only the legal speed is considered as a safety constraint.

PH2: six drivers drive the same vehicle on the same itinerary but with a preceding vehicle (safe headway spacing), to take into account the traffic conditions. 
Each driver must realize two different itineraries with two passing on each. The first two passing are covered without the EDAS, and it is demanded to the driver to make some effort about his eco-driving style. During their two last passing, the HMI display is offered to the driver. The objective is to see if the EDAS will bring a fuel gain compared to the eco-driving rules.

\section{PH1 phase}

Among the two considered drivers in PH1, one obtains a 1.8\% economical gain face to the second one that achieves a $9.7 \%$ economical gain. The question is : how to convince the first one to use this EDAS in spite of its weak economical gain?

Furthermore, the trip time increased of around $8 \%$ with an speed/gear number advice via a HMI, then the second question is: is it acceptable by the driver? In a accident gravity point of view, it can be viewed as a way to reduce the average speed thus to decrease the number of accidents.

Regarding now the legal speed overshoots, the use of the HMI brings a very high gain in respecting the legal speed even the first driver (gain of more tan 79\%), it is another one of the advantages of this EDAS.

The figure 5 presents the speed and engine torque profiles of the first driver on a $2.5 \mathrm{~km}$ journey, with two passings (with and without HMI). A negative value of the torque corresponds to the use of the engine braking. The pink plot is the engine brake use: when " 0 ", there is no brake. When there is the first legal speed changing, the driver begins to use the engine braking at the same moment on both trips. If we compare both trips with and without the HMI, one can see that without the HMI, the speed profile is always up to the one with the HMI. The reason is the following: as the EDAS uses an electronic horizon, it can anticipate on the different events to be coming, contrarily to the driver without any HMI. By this way, the HMI advice being anticipative, the driver can also anticipate its action by following the HMI output, at some moments where the ecodriving rules can be difficult to be applied without any indication like with an electronic horizon.

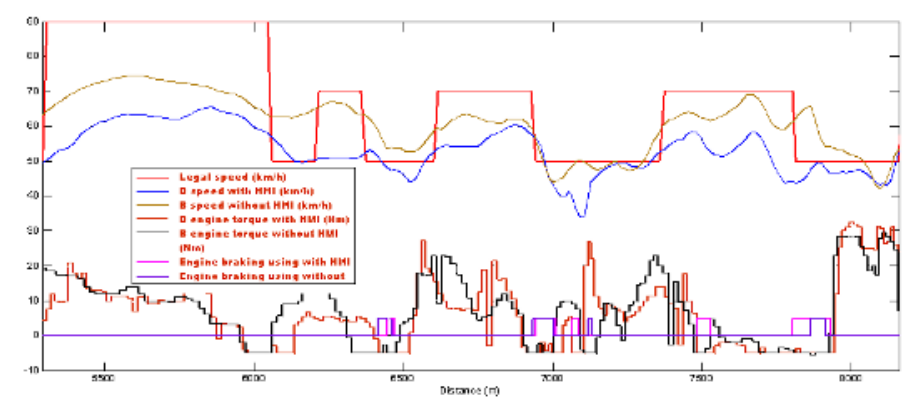

Fig. 5 - Speed and engine torque profiles of the first driver: use of engine braking.
Furthurmore, for the first driver, the engine braking is used at $29.96 \%$ of the total time during its two first passings face to 26.25 on his two last passings. This means that the engine braking can create an influence on the fuel consumption but it is not a dominant variable.

\section{PH2 Phase}

Now, a preceding vehicle is added in order the traffic conditions to be taken into account. All the six drivers $(\mathrm{C}, \mathrm{D}, \mathrm{S}, \mathrm{F}, \mathrm{G}, \mathrm{A})$ induce a fuel economy just by following the instructions of the HMI. This gain varies from $1.6 \%$ to $12.9 \%$, in function of the considered driver.

These gains begin to be significative for several drivers. Besides, without the HMI, all the drivers had made some efforts to eco-drive by applying the rules. So when we compare both experiences (with and without HMI), the gains are supposed a few.

The fuel consumption average of all the drivers without the HMI is $6.611 / 100 \mathrm{~km}$. With the HMI, it is $6.121 / 100 \mathrm{~km}$. The obtained fuel economy is then $7.55 \%$, what is the more, in real traffic conditions. It can be noted that, in a safety point of view, the gains are quite high with the use of the ADAS.

TABLE II. LEGAL SPEED OVERSHOOTS IN TRAFFIC REAL CONDITIONS.

\begin{tabular}{|c|c|c|l|}
\hline \multirow{2}{*}{ Driver } & \multicolumn{3}{|c|}{ Legal Speed Overshoots (\%) } \\
\cline { 2 - 4 } & Without HMI & With HMI & \multicolumn{1}{|c|}{ Gain (\%) } \\
\hline $\begin{array}{c}1^{\text {st }} \\
\text { driver } \\
\text { of PH1 }\end{array}$ & 18.3 & 3.38 & -79.23 \\
\hline C & 13.71 & 9.24 & $-32.6 \%$ \\
\hline D & 5.67 & 4.17 & $-26.4 \%$ \\
\hline S & 9.34 & 9.3 & $-0.42 \%$ \\
\hline F & 6.33 & 2.35 & $-62.8 \%$ \\
\hline G & 18.87 & 5.02 & $-73.39 \%$ \\
\hline A & 9.35 & 3.76 & $-59.78 \%$ \\
\hline
\end{tabular}

The table II indicates the different gains won in terms of legal speed overshoots by using the presented EDAS with some very encouraging results and so promising for this kind of built-in system. The ecoDriver project thus aims to improve these results in terms of the different objectives listed in this paper.

Besides, this experimental work was realized with a trial HMI, it is obviously not an ergonomic HMI. The ecoDriver project will help in delivering such an ergonomic HMI module, that will be usefull to prove the system efficiency.

\section{CONCLUSION}

The European FP7 ecoDriver project is presented in broad outline. An Ecological Driving Assistance System (EDAS), developed in ecoDriver project is presented in its built-in form. 
From the vehicle and fuel consumption modeling, energy consumption optimization, several tests are achieved with this EDAS and induce the evaluation of the gains obtained in terms of economy, ecology and safety. After several experimental tests with 8 different drivers, the results affirm that the conception of EDAS is promising, by obtaining around 9 to $12 \%$ fuel gain while improving the safety aspects.

\section{ACKNOWLEDGMENTS}

The research leading to these results has received funding from the European Union Seventh Framework Programme under grant agreement $\mathrm{n}^{\circ} 288611-$ ecoDriver project.

\section{REFERENCES}

[1] O. Carsten, http://www.ertico.com/interview-with-prof-olivercarsten-university-of-leeds-on-the-new-ecodriver-project/, ERTICO interview, Oct. 2011.

[2] HAVEit EU FP7 Project, http://www.haveit-eu.org, 2008-2011.

[3] eFuture EU FP7 Project, http://www.efuture-eu.org/, 2010-2013.

[4] Official US government website for distraction driving, http://www.distraction.gov/, 2011.

[5] AIDE EU FP6 IP Project, http://www.aide-eu.org/, 2008.

[6] ITERATE EU FP7 Project, http://www.iterate-project.eu/, 2011.

[7] TELEFOT EU FP7 Project, http://www.telefot.eu/, 2011.

[8] ECOMOVE EU FP7 Project, http://www.ecomove-project.eu/, 2011.

[9] PPP European Green Cars Initiative, http://www.green-carsinitiative.eu/public/, 2010.

[10] H-T.Luu, L. Nouvelière, S. Mammar, Modélisation de la consommation en carburant d'un véhicule léger à partir de données expérimentales, JD-JN-MACS, March 2009, Angers, France.

[11] H-T Luu, L. Nouvelière, S. Mammar, "Towards a Safer Ecological Driver Assistance System", Proceedings of the ITS World Congress, Oct. 2010, Busan,Korea.

[12] K. Ahn. Microscopic fuel consumption and emission modeling. Master's thesis, the Virginia Polytechnic Institute and State University, 1998.

[13] K. Ahn, H. Rakha, M. ASCE, A. Trani, and M. Van Aerde. Estimating vehicle fuel consumption and emissions based on instantaneous speed and acceleration levels. Journal of Transportation Engineering, $128: 182-190,32002$.
[14] M. Thomas and M. Ross. Developpement of second-bysecond fuel use and emissions model based on an early 1990s composite car, sae technical paper series, 97-1010, 1999. 
ANNEX A

VEHICLE DESCRIPTION FOR EDAS BUILT-IN SYSTEM

The aim of this model is to be mainly used on ICE (Internal Combustion Engine) vehicles. Parameters for each vehicle have to be set in the application. A "standard" vehicle can be selected if these parameters are not available. The application is tested on a RENAULT Clio 3 Eco 2 equipped with CAN bus fuel consumption measurements and fuel flow meters.

For the experimental applications, this test vehicle is also equipped with a datalogger named RTMAPS (Intempora France) that makes the interface between the $\mathrm{C} / \mathrm{C}++$ algorithm issued from the MATLAB/SIMULINK algorithms and the sensors/actuators.

The figure 6 and Table III respectively give a general view of the test vehicle and the main technical data about it.

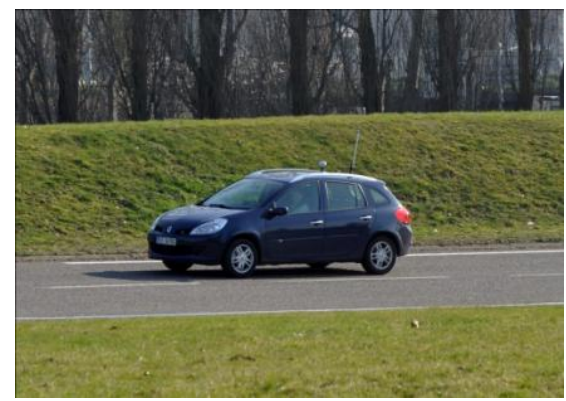

Fig. 6 - Test vehicle - RENAULT Clio 3 on Versailles-Satory (FR)
TABLE III. TeChNical data FOR RenAult CliO3 ECo 2.

\begin{tabular}{|c|c|c|}
\hline Engine & Data & Details \\
\hline & Fuel & Unleaded gasoline \\
\hline & Displacement & $1.21 \mathrm{TCE} 100$ \\
\hline & Max torque & 145 N.m@3000 tr.min ${ }^{-1}$ \\
\hline & Power & 74 kW @3000 tr.min ${ }^{-1}$ \\
\hline \multicolumn{3}{|l|}{ Gearbox } \\
\hline & Construction form & 5-speed (manual) \\
\hline & Gear ratios & $\mathrm{I}-3.7272$ \\
\hline & & II -2.0476 \\
\hline & & III -1.3929 \\
\hline & & IV - 1.0294 \\
\hline & & $\mathrm{V}-0.8205$ \\
\hline
\end{tabular}

\section{test track.}

\begin{tabular}{|l|l|l|}
\hline \multicolumn{1}{|c|}{ Engine } & Data & Details \\
\hline Differential & & \\
\hline & Ratio & 4.092 \\
\hline Vehicle & & \\
\hline & Weight & $1269 \mathrm{~kg}$ \\
\hline
\end{tabular}

